Document downloaded from:

http://hdl.handle.net/10251/99470

This paper must be cited as:

J. Antonino-Daviu; Riera-Guasp, M.; Pons Llinares, J.; Park, J.; Lee, SB.; Yoo, J.; Kral, C. (2012). Detection of Broken Outer-Cage Bars for Double-Cage Induction Motors Under the Startup Transient. IEEE Transactions on Industry Applications. 48(5):1539-1548. doi:10.1109/TIA.2012.2210173

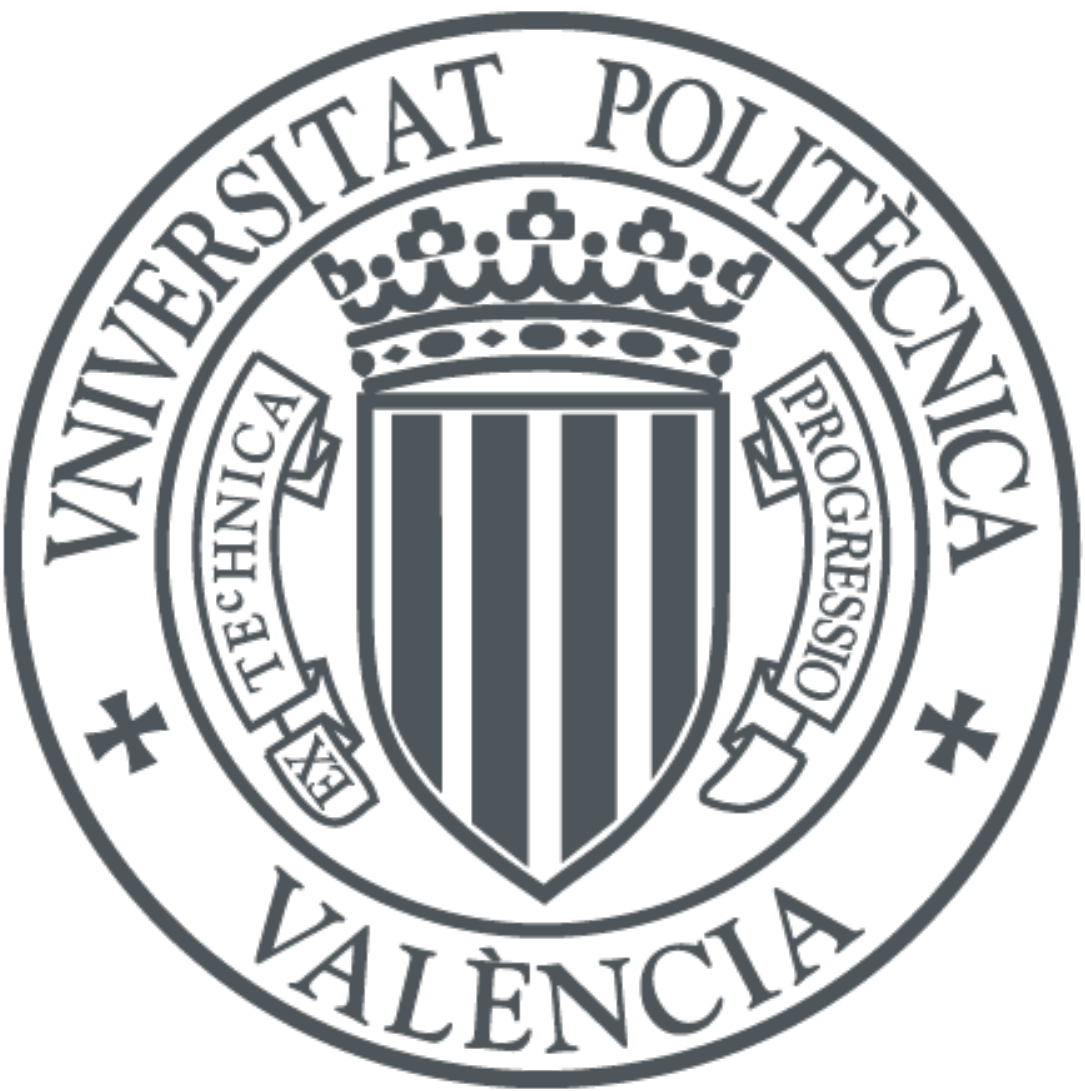

The final publication is available at

http://doi.org/10.1109/TIA.2012.2210173

Copyright Institute of Electrical and Electronics Engineers

Additional Information 


\title{
Detection of Broken Outer Cage Bars for Double Cage Induction Motors under the Startup Transient
}

\author{
Jose Antonino-Daviu, Martin Riera-Guasp, Joan Pons-Llinares, Jongbin Park, Sang Bin Lee, Jiyoon Yoo and \\ Christian Kral
}

\begin{abstract}
Unlike single cage rotor fault detection, FFTbased steady state spectrum analysis techniques can fail to detect outer cage faults in double cage induction motors due to the small outer cage current under running conditions. Double cage motors are typically employed in applications that require loaded starts. This makes the outer cage vulnerable to fatigue failure since it must withstand the high starting current and long startup time frequently. However, there are only a few publications that investigate detection techniques specifically for double cage motors. In this paper, considering that the influence of the faulty outer cage is strong at startup due to the large outer cage current, detection of outer cage faults under the startup transient is investigated. A Discrete Wavelet Transform-based method is proposed as a viable solution to detection of outer cage faults for double cage motors. An experimental study on fabricated copper double cage induction motors shows that the proposed method provides sensitive and reliable detection of double cage rotor faults compared to FFT.
\end{abstract}

Index Terms - AC Machine; Condition Monitoring; Double Cage Rotor; Fast Fourier Transform (FFT); Fault Diagnostics; Induction Motor; Motor Current Signature Analysis (MCSA); Outer Cage Fault; Transient Analysis; Wavelet Transform.

\section{INTRODUCTION}

I $\mathrm{T}$ has been shown in many resources that the outer cage of double squirrel-cage rotor induction motors is vulnerable to failure due to its structure and applications [1-4]. FFTbased steady state on-line spectrum analysis techniques can fail to detect outer cage faults for double cage motors due to the small outer cage current level under running conditions [5-7], unlike single cage rotor faults. However, there currently is no detection method studied specifically for outer cage fault detection. The goal of this paper is to develop a detection method sensitive to outer cage faults for reliable operation of double cage induction motors.

The double cage rotor is typically used in applications that require high starting torque such as conveyors, crushers, stirrers, and compressors, etc, and the design can be characterized by the relatively large outer bar resistance and inner bar leakage inductance, as shown in Fig. 1. The rotor

This work was supported in part by the Spanish "Ministerio de Educación y Ciencia", in the framework of the "Programa Nacional de proyectos de Investigación Fundamental", project reference DPI200806583/DPI and in part by a 2010 Korea University Grant (T1001961).

J. Antonino-Daviu, M. Riera-Guasp, and J. Pons-Llinares are with Departmento de Ingeniería Eléctrica, Universidad Politecnica de Valencia, Camino de Vera s/n, 46022 Valencia, SPAIN (e-mails: joanda@die.upv.es, mriera@die.upv.es,jpons@die.upv.es).

J. Park, S. B. Lee, and J. Yoo are with the Department of Electrical Engineering, Korea University, Seoul, Korea (e-mail: intheshine@ korea.ac.kr, sangbinlee@korea.ac.kr, jyyoo@korea.ac.kr).

C. Kral is with the Mobility Department of Austrian Institute of Technology, Vienna, Austria (e-mail: christian.kral@ait.ac.at). current is confined to the outer cage during the startup transient at high slip, $s$, due to the dominance of the high leakage inductance of the inner cage. Since double cage motors are used for loaded startups, the outer cage must handle the large starting current for the long acceleration time with limited path for heat dissipation (Fig. 1) compared to single cage deep bar rotors [3]. It is shown in [4] that it is not uncommon for the outer bar temperature rise to exceed $200^{\circ} \mathrm{C}$; therefore, the thermo-mechanical stresses combined with mechanical stresses, make the outer cage of double cage rotors vulnerable to fatigue failure. Broken outer cage bars also result in redistribution and increase of the current (and thermal stress) in the adjacent bars at motor startup causing breakage of additional bars. This degrades the starting performance (increase in startup time) of the motor until excessive heating or motor trip during startup (startup failure) becomes an unsustainable problem. Examples of double cage rotor failures with contiguous broken outer cage bars are shown in Fig. 2(a)-(b) for a $300 \mathrm{~kW}, 1 \mathrm{kV}$ coalmining gangway conveyor motor [4] and a $800 \mathrm{~kW}, 3.3 \mathrm{kV}$ pulp stirrer motor, respectively. For both cases, the problem with the rotor was discovered because the motor failed to start, and the inner cage bars were in good condition. For the motor shown in Fig. 2(b), the extreme heat developed due to broken outer cage bars resulted in "melting" and "breaking off" of copper bar pieces, which caused burning of the stator end winding insulation and core damage, and lead

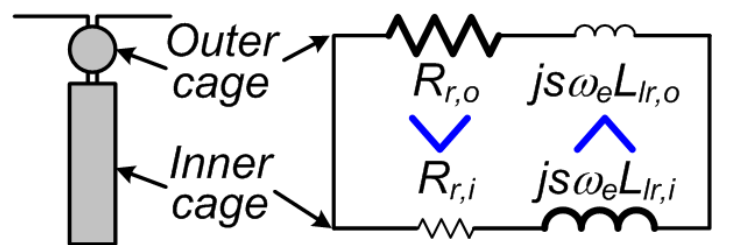

Fig. 1. Structure and electrical circuit representation of double cage rotor

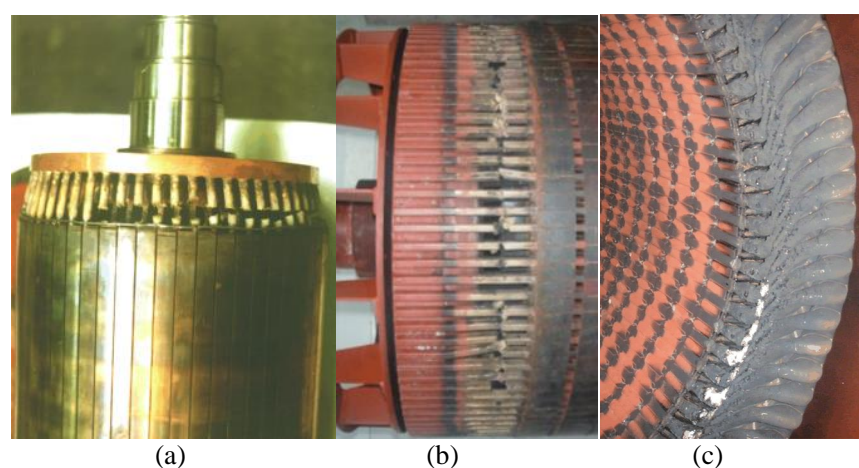

Fig. 2. Photographs of (a) $300 \mathrm{~kW}, 1 \mathrm{kV}$ mining gangway conveyor [4] and (b) $800 \mathrm{~kW}, 3.3 \mathrm{kV}$ pulp stirrer double cage induction motor rotors that failed to start due to broken outer cage bars (inner bars healthy); (c) stator of the motor shown in (b) 
to un-repairable motor failure (Fig. 2(c)).

The problem of detecting outer cage faults of double cage motors is completely different from that of single cage motors as they are vulnerable to failure and difficult to detect on-line. However, fault detection of double cage motors has not received much attention from the research community. According to a thorough literature survey, only 3 papers related to fault detection of double cage motors have been published [5-7]. In [5], it is shown that broken bars in fabricated copper double cage induction motors are difficult to detect due to the presence of significant inter-bar currents. In [6], a steady state model for inner and outer bar failures is derived, and the problem of detecting outer cage failures in steady state based on a theoretical analysis of their model is addressed. The authors suggest the negative sequence impedance as a means of detecting outer cage failures; however, the feasibility has not been verified under actual motor operation. In [7], an analytic and experimental evaluation of the detectability of broken outer cage bars is presented. It is clearly shown that outer cage faults are very difficult to detect with FFT-based steady state techniques, and that they can be observed with higher sensitivity with standstill tests when the motor is at high slip due to the higher outer cage current.

The aim of this work is to investigate the feasibility of using transient analysis to detect outer cage bar breakages, as well as to point out its advantages and drawbacks with respect to the conventional steady-state analysis.

Based on the observation of higher detection sensitivity of outer cage faults at high slip, fault detection under the startup transient is investigated in this paper. Though there are many possible time-frequency decomposition tools that could be applied [14-16, 19-20], in this paper a Discrete Wavelet Transform (DWT)-based method is proposed and verified to improve the sensitivity and reliability of fault detection of double cage rotor faults compared to FFT.

\section{DETECTABILITY OF OUTER CAGE FAULTS FOR DOUBLE SQUIRREL CAGE ROTOR INDUCTION MOTORS}

The detectability of outer cage faults can be explained from the rotor current distribution in the two bars of double cage rotor induction motors [7-9]. In the startup transient, the high slip makes the high leakage inductance of the inner bar dominant, and confines the rotor current to the outer bar, as can be seen in Figs. 1,3. As the rotor accelerates, the slip decreases and makes the high resistance of the outer bar dominant, which results in transitioning of the current from the outer to inner bar. An example of the rotor bar current distribution as a function of rotor speed (slip) for a $25 \mathrm{hp}$ common end ring double cage motor is shown in Fig. 3 [8].

FFT based detection of rotor faults relies on indirectly observing the influence of the asymmetry in the rotor flux pattern due to the re-distribution of the current caused by the broken bar. The frequency spectrum of the speed, vibration, torque, axial/radial flux, or current measurement can be used for broken bar detection [10]. When monitoring the current spectrum (MCSA), the component below is observed under steady state operation for rotor fault diagnosis, where $f_{e}$ is the fundamental frequency, and $s$ is the slip.

$$
f_{L S C}=(1-2 s) \cdot f_{e}
$$

It has been shown in [10-11] that the magnitude of $f_{L S C}$ is proportional to the "magnitude of the rotor current" for a given severity of fault. Since it is the asymmetry in the rotor current distribution due to broken bars that is observed, a strong signature for detection can be obtained if the rotor current is large. Therefore, it can be deduced that FFTbased steady state spectrum analysis would not be sensitive to outer cage faults since the outer cage current is small under steady state operating conditions, as shown in Fig. 3.

The sensitivity of MCSA has been experimentally evaluated in [7] for single cage deep bar and double cage common and separate end ring rotor designs. It can be seen in the MCSA results under rated load conditions shown in Fig. 4 that the sensitivity of MCSA is significantly deteriorated for the broken outer bars of fabricated double cage rotors when compared to the broken single cage bar under identical fault conditions. The $f_{L S C}$ component is relatively lower by $8-12 \mathrm{~dB}$ and $18-22 \mathrm{~dB}$ for the common and separate end ring designs, respectively, which corresponds to a decrease in sensitivity by a factor of X3-4 and X8-12.

Considering that the default fault alarm level for broken

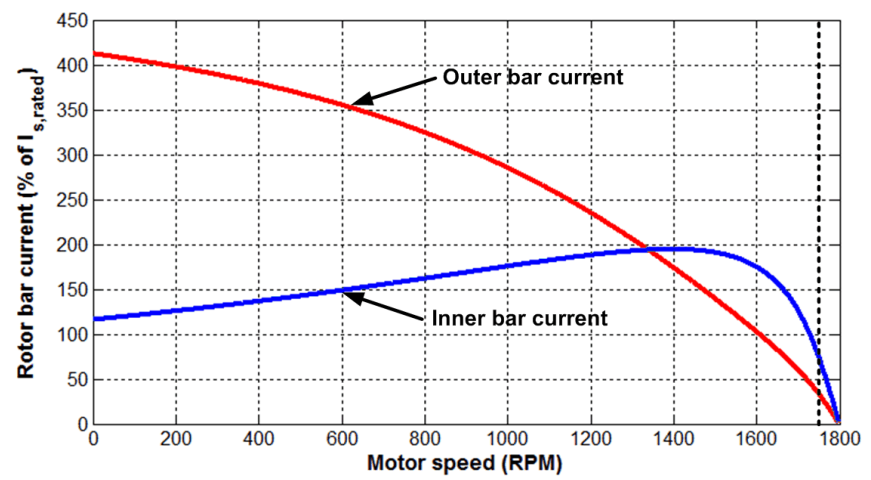

Fig. 3. Rotor current distribution in inner and outer bars of double cage rotor as a function of speed (slip) (25hp common end ring rotor)

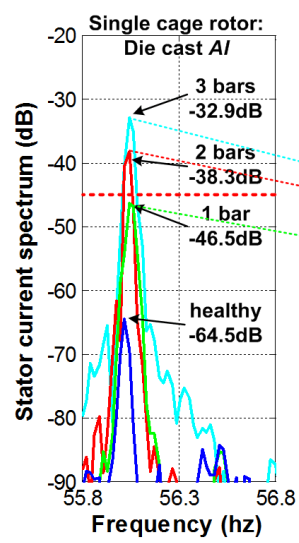

(a)

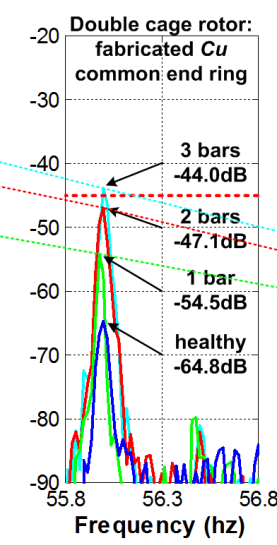

(b)

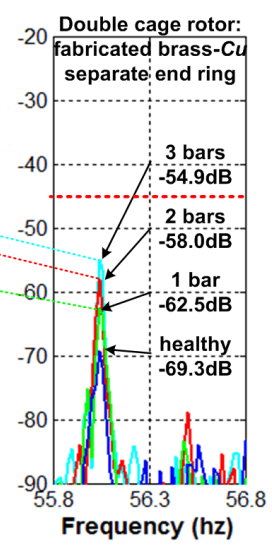

(c)
Fig. 4. Experimental measurements of broken bar component, $f_{L S C}$, with online MCSA under rated load for 0-3/44 broken bars for (a) single cage deep bar $\mathrm{Al}$ die cast rotor; double cage fabricated (b) $\mathrm{Cu}$ common end ring rotor; (c) brass- $\mathrm{Cu}$ separate end ring rotor [7] 
bars is set at -45 -35dB in commercial MCSA products (to avoid false alarms) [12-13], outer cage faults of double cage motors are unlikely to be detected, as can be seen in Fig. 4. The higher background noise level, load variations, or coupling/load related characteristics or other problems that produce components in the vicinity of (1) in the field environment may all obscure fault detection. In addition, the fact that whether the rotor is of single or double cage construction is unknown in the field in most cases makes the fault extremely difficult to detect.

The arguments above clearly show that FFT-based steady state spectrum analysis cannot provide sensitive or reliable assessment for outer cage faults of double cage motors. Fault detection under the startup transient can therefore be considered as an alternate option since the sensitivity to outer cage faults is expected to be high (due to the high outer cage current under high slip operation). In this paper, the DWT is used for analyzing the current during the startup transient to take advantage of the high sensitivity due to large outer cage current. The DWT has been successfully applied to startup transient fault detection for single cage motors in [1416], but has not yet been applied to double cage motors. The possible advantages of applying DWT in the startup transient compared to steady state FFT techniques for double cage motors can be summarized as follows:

- Higher sensitivity compared to steady state FFT techniques due to higher outer cage current

- Fault detection independent of load transients, oscillations, or interference

- Detection of problem when thermo-mechanical stress is maximum (allows early detection of faults that could be unobservable under standstill or light load conditions when thermal or centrifugal stress is small)

- Clear separation from fundamental component (can avoid spectral leakage problems under light load conditions or for high-efficiency motors)

- Slip (speed) measurement or estimation not required

- Testing possible without load at motor repair or manufacturing facilities (with reduced voltage startup or for large motors with high inertia)

\section{DWT-BASED BROKEN OUTER CAGE BAR DETECTION}

\section{A. Basic Principles of the DWT}

The DWT performs decomposition of a signal into multiple components that contain different frequency ranges of the original signal according to predetermined frequency bands. This makes DWT a powerful tool for analyzing non-stationary signals with variable frequency components, and it has been successfully applied to detection of electric machine faults [14-16]. Moreover, the implementation of the DWT based on the Mallat algorithm makes it a tool with low computational requirements in comparison with other time frequency decomposition tools and FFT. According to [17], the FFT algorithm for computing the DFT requires $O(N \cdot \log (N))$ operations whereas DWT requires $O(N)$ operations, where $N$ is the length of the analyzed signal and $O(\cdot)$ is the order of the number of operations required $(O(\cdot)$ is a function used for comparing the relative computational complexity). This makes it ideal for the purposes outlined in I-II, and is one of the main reasons justifying the selection of the proposed DWT method in this paper.

The application of DWT to a certain signal $i(t)$ (e.g. the startup current), sampled at a sampling rate $f_{s}$, enables the decomposition of the signal into several wavelet signals. The mathematical expression characterizing the DWT decomposition is given by (2), where $\alpha_{i}^{n}, \beta_{i}{ }^{j}$ are the scaling and wavelet coefficients, respectively; $\varphi^{n}(t), \psi^{j}(t)$ are the scaling function at level $n$ and wavelet function at level $j$, respectively, and $n$ is the decomposition level, which can be arbitrarily selected [14]. In this expansion, the first summation gives a function that is a low resolution or coarse representation of $i(t)$ (which is usually known as approximation signal, $a_{n}$ ). On the other hand, for each increasing index $j$ in the second summation, a higher or finer resolution is added, which adds increasing detail. The successive detail functions added for each value of $j$ are called detail signals $d_{j}$. In the expression, index $i$ is the translation index, whereas $j$ is called scale parameter. A detailed explanation of (2) can be found in [17].

$$
i(t)=\sum_{i} \alpha_{i}^{n} \cdot \varphi_{i}^{n}(t)+\sum_{j=1}^{n} \sum_{i} \beta_{i}^{j} \cdot \psi_{i}^{j}(t)=a_{n}+d_{n}+\ldots+d_{1}
$$

The most important idea underlying the application of the

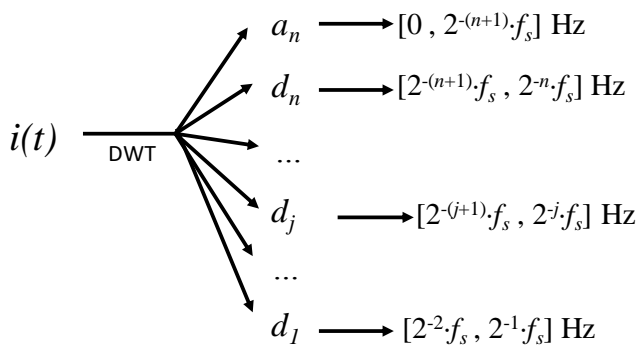

Fig. 5. Decomposition process carried out by DWT
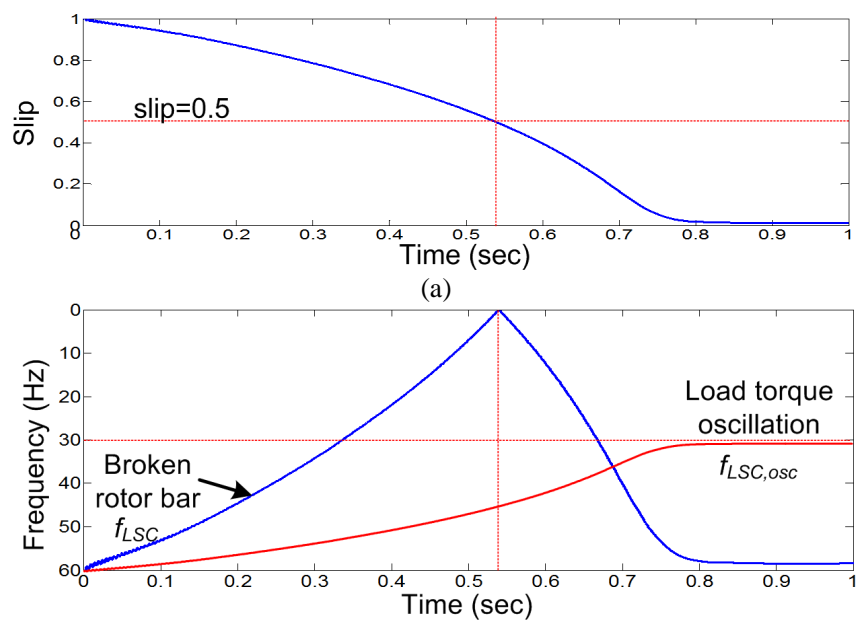

(b)

Fig. 6. (a) Slip evolution and (b) evolution of the broken rotor bar, $f_{L S C},(\Lambda$ shaped) and load torque oscillation, $f_{L S C \text {,osc }}$, during a direct on-line startup transient 
DWT is that each wavelet signal is associated with a certain frequency band, i.e., it extracts the time-evolution of the frequency components of the original signal which are included within the band. The range of the band covered by each wavelet signal depends on $f_{s}$ and on the level of the wavelet signal, as illustrated in Fig. 5.

\section{B. Extraction of $f_{L S C}$ through the DWT}

It was shown in [14] that during the direct on-line startup transient, while the slip $s$ varies between 1 and close to 0 , the $f_{L S C}$ component shown in (1) associated with broken rotor bars also changes. At the instant the motor source switch is closed, $\left|f_{L S C}\right|$ is equal to $f_{e}(s=1)$, and it decreases to $0(s=1 / 2)$, and increases back to a value close to $f_{e}$ as $s$ approaches 0 . This leads to a characteristic $\Lambda$-shaped evolution of the $\left|f_{L S C}\right|$, similar to that illustrated in Fig. 6(b), which has been obtained for a 4P, $1.1 \mathrm{~kW}$ induction motor under startup (slip evolution shown in Fig. 6(a)). If the DWT is applied to the startup current signal of a machine with broken bars, the evolution of $\left|f_{L S C}\right|$ will be reflected in the wavelet signals covering the frequency band of $0 \sim f_{e} \mathrm{~Hz}$; therefore, these signals can be used as reliable indicators of the fault [14]. This can be clearly observed in Figs. 7(a)-(b), which show the startup current, $i$, and high-level wavelet signals $\left(a_{10^{-}}\right.$ approximation signal; $\mathrm{d}_{10}, \mathrm{~d}_{9}$-detail signals) resulting from the DWT of $i$ for motors with 0 and 2 broken bars, respectively. These wavelet signals cover the frequency range of $0 \sim 29 \mathrm{~Hz}$, for the specific case analyzed $\left(f_{s}=15 \mathrm{kHz}\right.$ and $n=10$ decomposition levels). The oscillations in the wavelet signals for the faulty case are caused by the transient evolution of $\left|f_{L S C}\right|$ and they are consequently arranged in the characteristic $\Lambda$-shape shown in Fig. 6(b). A detailed characterization of this pattern can be found in [21].

One important issue is that the fault frequency range

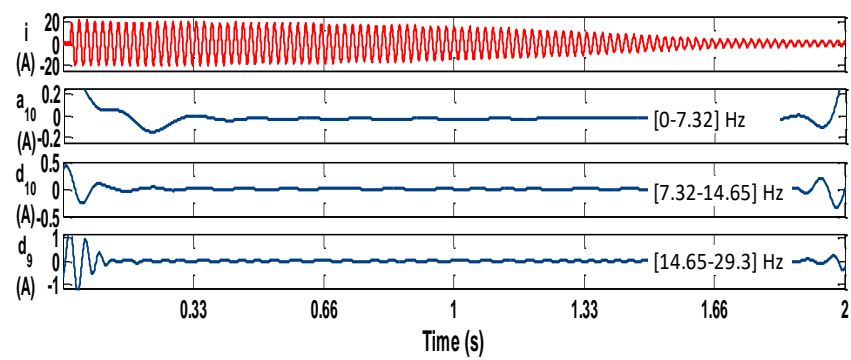

(a)

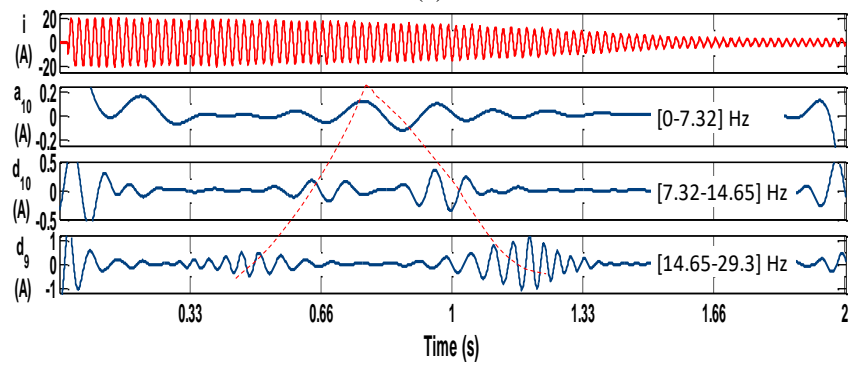

(b)

Fig. 7. Startup current, $i$, and high-level wavelet signals, $a_{10}, d_{10}, d_{9}$, resulting from the DWT of the startup current for: (a) healthy machine, (b) machine with 2 broken bars. should be covered by the considered high-level wavelet signals. Theoretically, the optimum frequency band would be between 0 and $f_{e}$, since the complete evolution of the $\left|f_{L S C}\right|$ during the transient is circumscribed to that band. However, additional aspects should also be considered:

- The filtering carried out by the DWT is not ideal, despite using suitable families such as high-order Daubechies or dmeyer [18]. The use of these mother wavelets greatly enhances the filtering performed in the sub-band coding algorithm, due to the good frequency response achieved with the high number of coefficients of the associated filters [17]. In this paper, dmeyer wavelet (102 filter coefficients) is adopted as mother wavelet in all DWT analyses. However, even when using these families, there can be a partial filtering of the fundamental component within the adjacent wavelet signal, masking the evolution of components present in that signal. Keeping the upper limit of the considered band not too close to $f_{e}$ is a way of avoiding this situation (e.g. 40 45 Hz upper limit is used for $f_{e}=60 \mathrm{~Hz}$ ).

- When an induction motor is started up from standstill, electromagnetic transients (EMT) take place regardless of the motor condition. The EMT provokes low frequency oscillations in the wavelet signals, as can be observed in Fig. 7. However, these oscillations last for a short time, being the pattern clearly observable in the wavelet signals after the EMT is finished.

- Position-dependent load torque oscillations, shown in (3), which are encountered in many industrial applications, can partially mask the evolution of $\left|f_{L S C}\right|$, due to the transient evolution of their associated components. For a 4P machine, the main torque oscillation component would evolve from $f_{e}(=60 \mathrm{~Hz})$ to near $f_{e} / 2(=30 \mathrm{~Hz})$ as slip decreases from 1 to near 0 , as shown in Fig. 6(b). The interference with these oscillations can be avoided by constricting the analyses to the band of $\left[0-f_{e} / 2\right] \mathrm{Hz}$.

$$
f_{L S C, \text { osc }}=(1-(1-s) / p) \cdot f_{e}
$$

DWT is a flexible tool since it enables analysis of different wavelet bands simply by changing the sampling rate $f_{s}$. For the case under study for $4 \mathrm{P}$ motors, $f_{s}$ was selected so that a simple algorithm can be used for detecting outer cage faults without the influence of possible load torque oscillations $\left(\left[0-f_{e} / 2\right] \mathrm{Hz}\right)$.

As a general recommendation for the application of the approach, considering the previous comments as well as the guidelines provided in $[14,18]$, a possible expression for the number of decomposition levels to develop the DWT would be given by:

$$
n_{f}=\text { integer }\left[\frac{\log \left(f_{s} / f\right)}{\log (2)}\right]+3
$$

\section{Quantification Parameters}

The identification of the $\Lambda$-shaped pattern in the high level wavelet signals resulting from the DWT is a reliable 
indicator of the presence of $f_{L S C}$, and therefore, of the existence of the outer cage faults in the machine, since it is very unlikely to have a similar pattern caused by a different fault or phenomena. Nonetheless, qualitative identification of the $\Lambda$-shaped pattern does not provide automated detection of the fault (fault existence) or information on the severity of fault. Therefore, it is necessary to define nondimensional indicators capable of quantifying the severity of the fault in the machine for clearly distinguishing healthy and faulty motors, also for complementing the information provided by the $\Lambda$ pattern. Although there could be a number of wavelet-based parameters that can be defined for quantification of fault severity, an energy-based parameter is proposed in this work for simplicity of the algorithm.

If broken outer cage bars exist, the energy levels of the high-level wavelet signals resulting from the DWT analysis of the startup current increase at high slip, due to the oscillations caused in those signals by the transient evolution of $\left|f_{L S C}\right|$. Moreover, the higher the level of failure is, the higher the level of oscillations and energy of these wavelet signals. Therefore, a quantification parameter based on the energy level of any of the wavelet signals affected by $\left|f_{L S C}\right|$ $\left(\mathrm{a}_{10}, \mathrm{~d}_{10}\right.$, or $\mathrm{d}_{9}$ in Fig.7) can be introduced. In order to normalize this parameter, for making it independent of the operation conditions of the machine (driven inertia, level of load, etc...), the energy of the considered wavelet signal is related to the total energy of the startup current signal. The result is the parameter $E_{n}$ defined as

$$
E_{n}(d B)=10 \cdot \log \left(\sum_{j=N b}^{N s} w a v(j)^{2} / \sum_{j=N b}^{N s} i_{j}^{2}\right)
$$

where $i_{j}$ is the value of the $j$ th sample of the current signal; $\operatorname{wav}(j)$ is the $j$ th sample of the wavelet signal considered for the analysis; $w a v(j)$ denotes any high-order detail signal or even the approximation signal resulting from the DWT decomposition and covering any portion of the frequency range in which $f_{L S C}$ evolves. In the paper, different high-order wavelet signals are evaluated to determine the most sensitive indicator; $N_{s}$ is the number of samples of the signal before reaching the steady-state regime, and $N_{b}$ is the number of samples between the origin of the signals and the extinction of the oscillations due to border effect. For instance, in Fig.7, $\underline{N}_{b}=0,33 \mathrm{~s} \times 15.000 \mathrm{samples} / \mathrm{s}=5.000$ samples; $N_{s}=1,33 \mathrm{~s} \mathrm{x}$ 15.000 samples $/ \mathrm{s}=20.000$ samples. According to this definition, the value of the parameter $E_{n}$ increases with fault severity. It should be noted that the computation of $E_{n}$ is extremely simple, and that it can also provide a reliable assessment of the outer cage condition if the band is selected so that load torque oscillations are avoided.

\section{EXPERIMENTAL STUDY}

\section{A. Experimental Setup}

To verify the effectiveness of the proposed method, an experimental study was performed on a $4 \mathrm{P}, 380 \mathrm{~V}, 7.5 \mathrm{hp}$ induction motor. The original rotor of this test motor is an
$A l$ die cast deep bar rotor with 44 rotor slots (sample 1). To test double cage motors, two 44 slot fabricated copper bar double cage rotors (samples 2 and 3 ) were designed and built to fit the stator of the original motor. The 3 rotor test samples are summarized as follows, and shown in Fig. 8.

- Sample 1: Single cage deep bar, Al die-cast rotor

- Sample 2: Double cage, fabricated $C u$ bar rotor with common end ring

- Sample 3: Double cage, fabricated $\mathrm{Cu}$ bar rotor with separate end ring (brass outer cage)

Fabricated rotors with $\mathrm{Cu}$ bars were built for the study because they are more representative of large motors, as motors rated above $500 \mathrm{hp}$ are typically fabricated $\mathrm{Cu}$ rotor type. The inner and outer bars are usually electrically connected throughout the axial length for $A l$ die cast rotors for conduction of heat to the inner bar at startup; therefore, broken outer bars would not prevent current from flowing in the outer bars. Therefore, testing with $A l$ die cast rotors is meaningless as it does not represent a broken outer cage bar for large machines. The design and manufacturing of the two double cage rotors was based on the typical design rules and processes used for large motors.

The bar and end ring design for the two double cage fabricated rotors with common (sample 2, Fig. 8(b)) and separate (sample 3, Fig. 8(c)) end rings are shown in Fig. 9(a)-(b), respectively. Although there is a cost advantage for the common end ring design, the separate end ring design is more common as it provides higher starting torque (higher

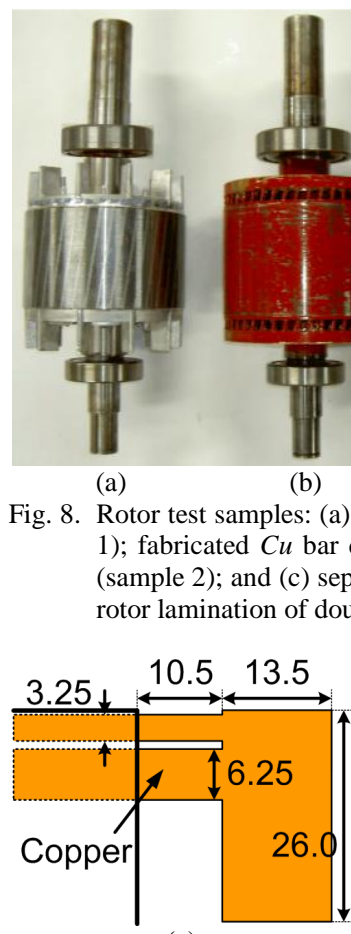

(a)

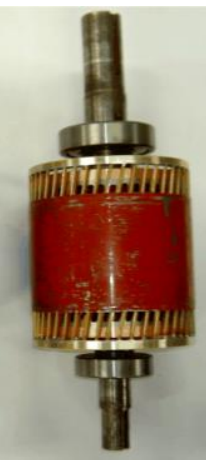

$\begin{array}{llll}\text { Fig. 8. Rotor test samples: (a) original } A l \text { die cast single cage rotor (sample } & \text { (c) }\end{array}$

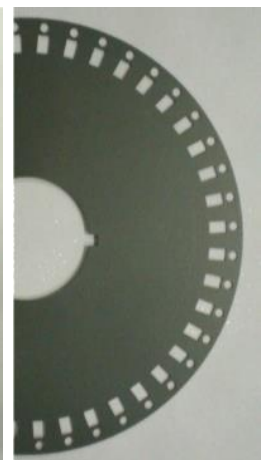

$\begin{array}{llll}\text { Fig. 8. Rotor test samples: (a) original } A l \text { die cast single cage rotor (sample } & \text { (c) }\end{array}$ 1); fabricated $\mathrm{Cu}$ bar double cage rotor with (b) common end ring (sample 2); and (c) separate end ring (brass outer bar, sample 3); (d) rotor lamination of double cage fabricated $\mathrm{Cu}$ rotors (samples 2-3)

Fig. 9. Bar and end ring design for (a) common end ring rotor (sample 2, Fig. 5(b)) and (b) separate end ring rotor (sample 3, Fig. 5(c))

Table I. Frequency bands for the considered wavelet signals with $f_{s}=15 \mathrm{kHz}$

\begin{tabular}{|c|c|c|c|}
\hline Signal & $d_{9}$ & $d_{10}$ & $a_{10}$ \\
\hline Frequency band $(\mathrm{Hz})$ & $14.65 \sim 29.3$ & $7.32 \sim 14.65$ & $0 \sim 7.32$ \\
\hline
\end{tabular}


outer cage resistance) and is less susceptible to breakage due to the independent contraction and expansion of the two cages (less thermo-mechanical stress at bar and end ring joint). The outer cage is usually made of high resistivity material such as brass or bronze for higher starting torque $[2,8]$. To simulate broken bar conditions, the contact between the rotor bars and end rings were cut at the outer bar-end ring joint for up to 3 of 44 bars.

To produce the startup time typically experienced for double cage rotors, a steel disc was attached to the shaft of the unloaded motor. The thickness and radius of the disc were carefully designed so that the startup time is between 1.0 and 1.5 secs. The motor was not loaded and nothing was connected to the rotor shaft other than the inertia disc, to observe the fault detectability under the worst case condition. Based on the experience of the authors, the sensitivity of DWT-based startup fault detection is significantly improved with increase in motor load. The performance of the proposed algorithm is therefore verified purely for the startup transient under high slip operation, and not for low slip steady state load.

\section{B. Experimental Results}

The startup currents of one phase for the three motor samples were sampled at $15 \mathrm{kHz}$ with a commercial current sensor and data acquisition tool. The sampling rate was selected to constrict the analyses to a band below $f_{e} / 2(\sim 30$ $\mathrm{Hz}$ ) to avoid the potential effects of position-dependent load torque oscillations using a simple algorithm. Selection of this frequency range also prevents the fault indicator from being influenced by non-ideal filtering of the main frequency, $f_{e}$, as described in III.B. The corresponding frequency bands covered by the considered wavelet signals are shown in Table I (dmeyer was used as the mother wavelet).

\section{1) Qualitative Patterns}

The waveforms of the startup current, and $a_{10}, d_{10}, d_{9}$ wavelet signals for the three motor samples are shown in Figs. 10 12, respectively, to represent the DWT analyses for the four different cases of $0,1,2$, and 3 broken outer cage bars. The graphs are represented with a similar scale for all the cases corresponding to a specific motor, for ease of comparison between the different fault conditions.

The $\Lambda$-shaped pattern in the high-level wavelet signals can be clearly noticed in all faulty cases as shown in the figures. For each particular motor, it can be seen that the oscillations in the wavelet signals increase for a more severe fault condition. This confirms the fact that the energy levels of the high-level wavelet signals constitute good indicators on the existence and severity of outer cage failure in the machine. Note that the magnitudes of the oscillations, for a similar fault condition, depend on the type of motor, being more prominent for the single cage motor. This is not surprising considering that the bar is fully broken for single cage motors, whereas it is only partially broken for double cage motors. Single cage motor failures would be more easily detectable independent of the method used for fault detection for this reason.
It is also added that it was shown in recent work that automatic detection of these patterns in the DWT signals is possible [22]. This enables the reliability of fault detection to be improved; however, it is not applied here as it is not within the scope of this paper.

\section{2) Quantification Indicator}

The energy-based wavelet indicator, $E_{n}$, can be calculated from the energy of any of the wavelet signals under consideration (in our case, $a_{10}, d_{10}$, or $d_{9}$ ). Several possibilities were studied based on the comparison of individual and combination of wavelet signals $d_{9}, d_{10}$, and $a_{10}$. The results show that the most sensitive indicator

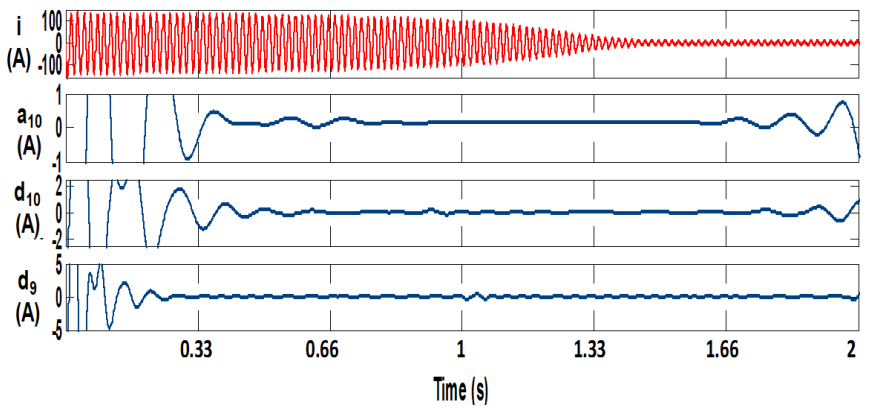

(a)

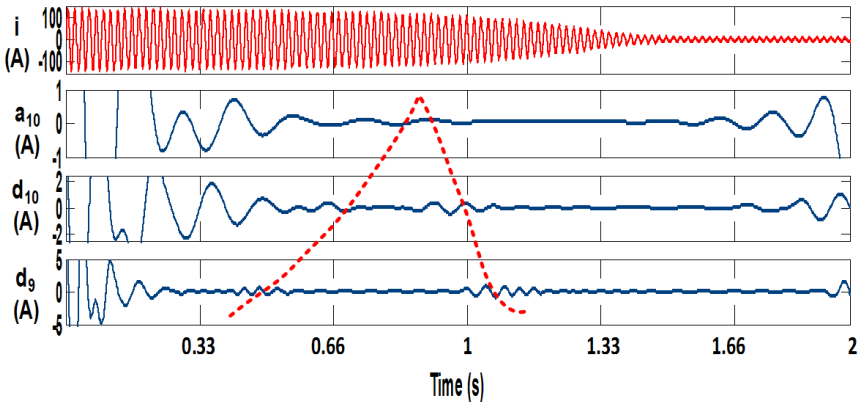

(b)

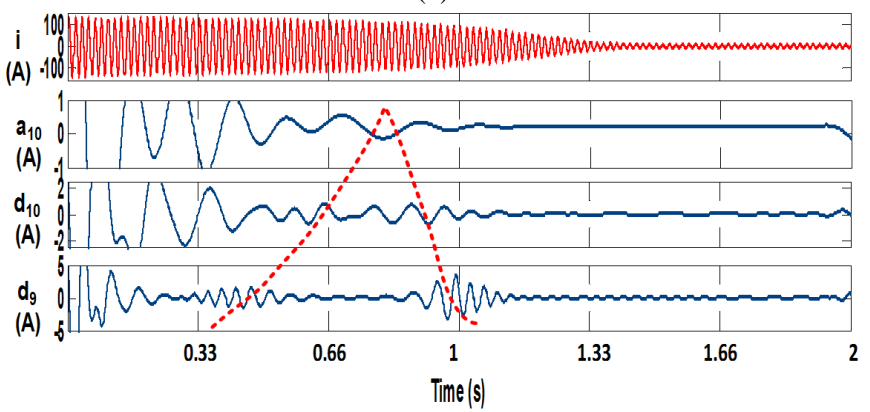

(c)

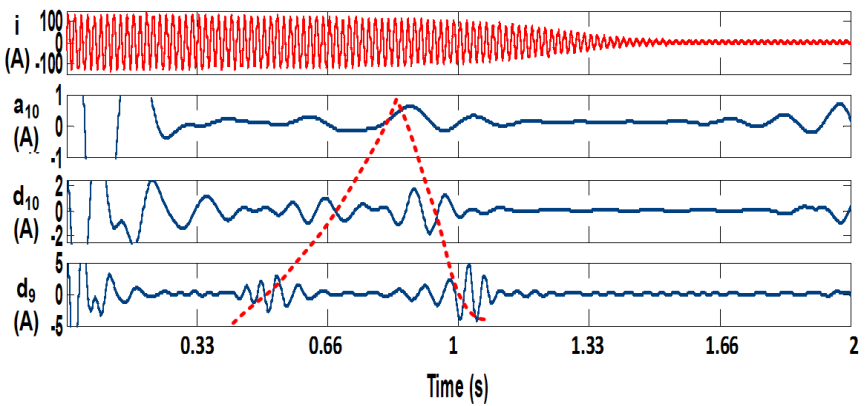

(d)

Fig. 10.DWT analysis of the startup current: $a_{10}, d_{10}$, and $d_{9}$ wavelet signals under the startup transient for sample 1 (single cage $A l$ die cast rotor) with (a) 0 ; (b) 1; (c) 2; and (d) 3 broken bars 
is based on the sum of the energies of signals $d_{9}$ and $d_{10}$ for all three motor samples. The frequency band taken into consideration for the energy computation is therefore [7.32-29.3] Hz. This is quite logical since the very low frequency range is discarded, which enables elimination of the startup EMT. As commented in III.B, EMT provokes low frequency oscillations in the wavelet signals (clearly visible in $a_{10}$ ) which lead to a decrease in the difference between healthy and faulty conditions thus reducing the sensitivity.

The values of the $E_{n}$ indicators calculated from the $d_{9}$ and $d_{10}$

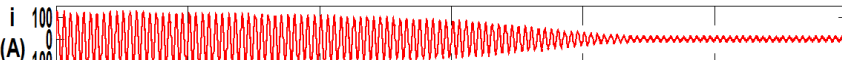
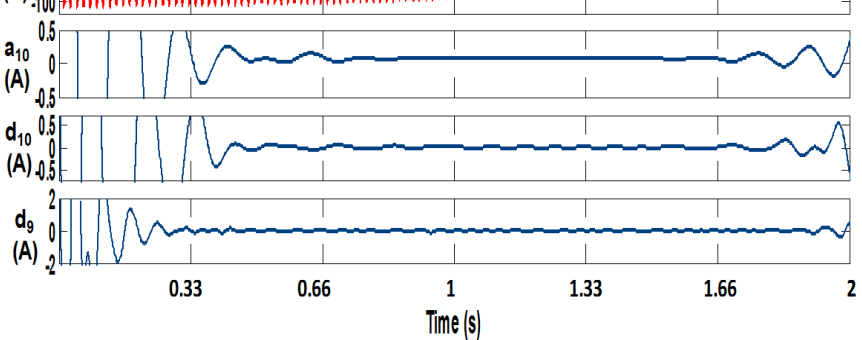

(a)

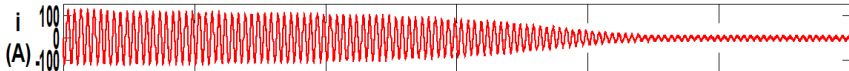

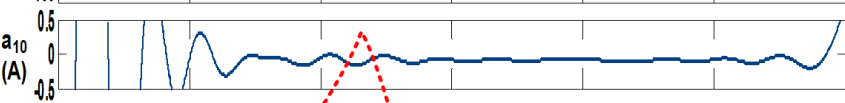

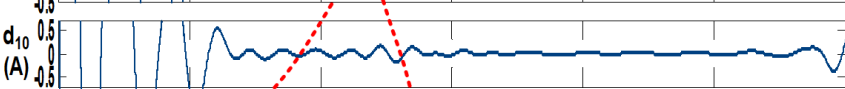

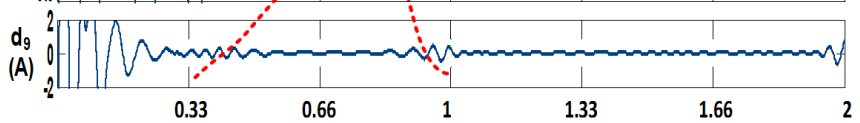

Iime

(b)

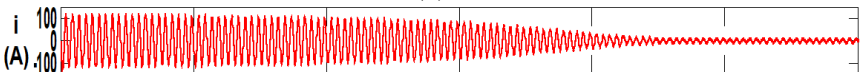

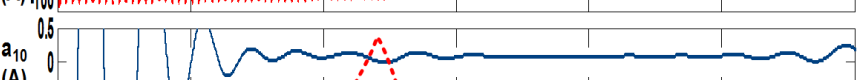

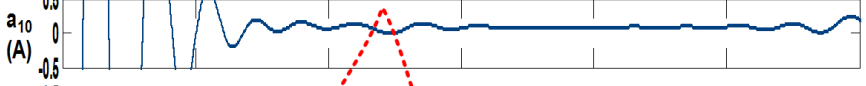
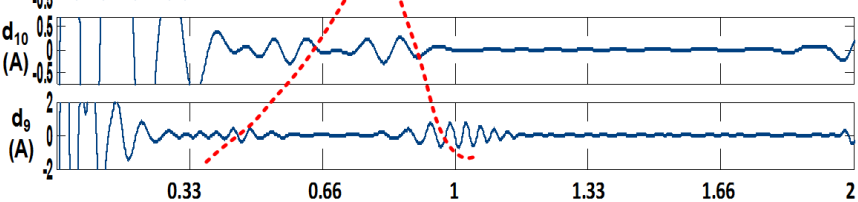

Time $(\mathbf{s})$

(c)

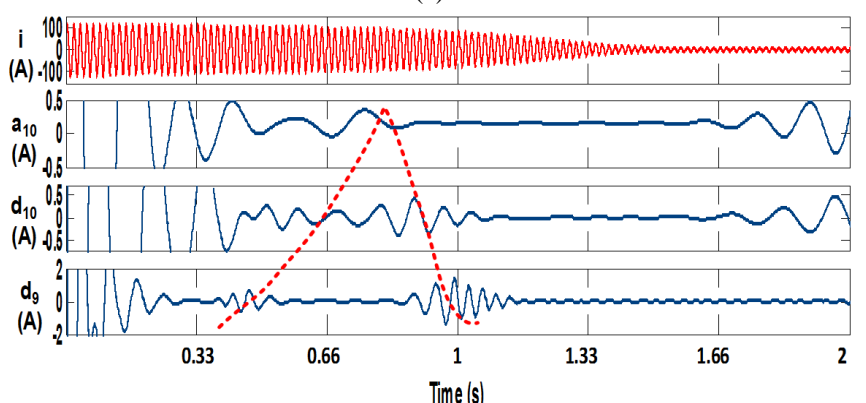

(d)

Fig. 11.DWT analysis of the startup current: $a_{10}, d_{10}$, and $d_{9}$ wavelet signals under the startup transient for sample 2 (double cage common end ring fabricated $\mathrm{Cu}$ rotor) with (a) 0 ; (b) 1; (c) 2; and (d) 3 broken outer cage bars wavelet signals are summarized in Table II for the three motor samples. The increase in the $\mathrm{dB}$ levels of the fault quantification indicator $E_{n}$ with the number of broken bars for the three samples is also plotted in Fig. 13 to show the change in $E_{n}$ visually. It can be observed from the fault indicator that broken (outer cage) bars can be detected clearly with high sensitivity (samples 2 and 3). The energy level between the healthy and faulty samples can be clearly distinguished without ambiguity, and it is unlikely to be influenced by transients or oscillations in the load as in the case of FFT. It is meaningless to compare the results shown in Figs. 10-

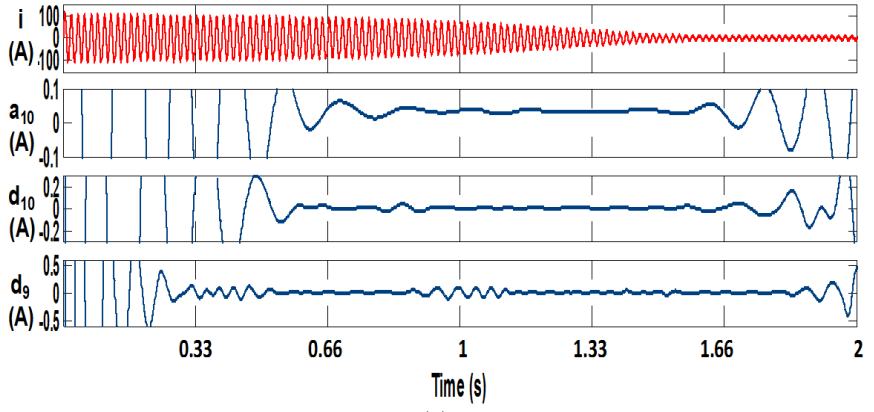

(a)

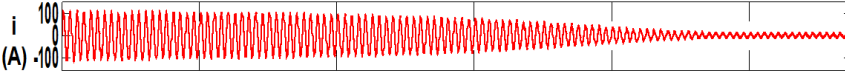
(A) 100 tor \begin{tabular}{ll|l|l|l|l|l|l|l|}
$a_{10}$ \\
(A)
\end{tabular} (A) $\begin{aligned} & d_{10} \\ & \text { (.2. }\end{aligned}$

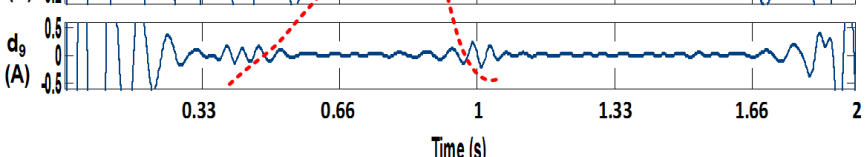

(b)

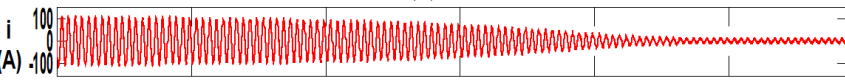

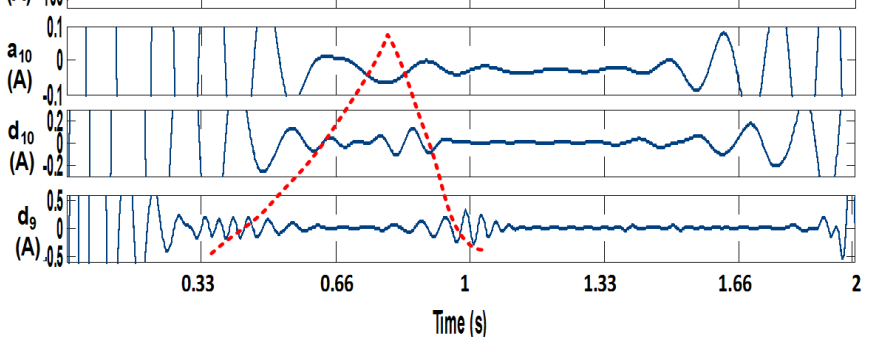

(c)

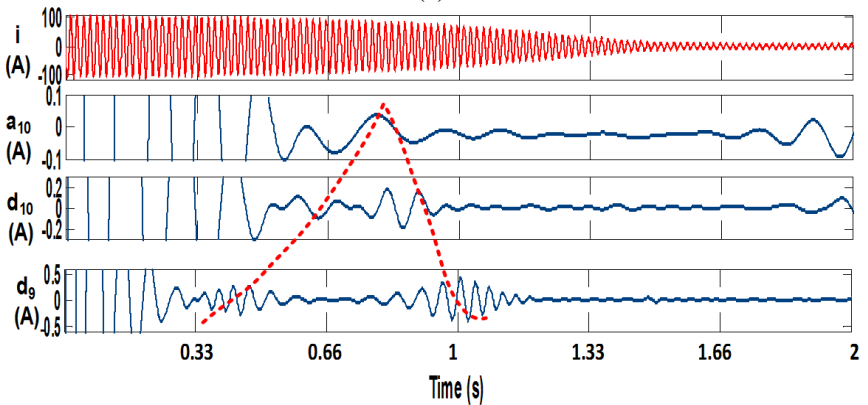

(d) under the startup transient for sample 3 (double cage separate end ring rotor with fabricated $\mathrm{Cu}$ inner cage and brass outer cage) with (a) 0 ; (b) 1 ; (c) 2; and (d) 3 broken outer cage bars 
Table II. Values of $E_{n}$ for the motor samples for $0 \sim 3$ broken outer cage bars

\begin{tabular}{|c|c|c|c|c|}
\hline \multirow{2}{*}{$\begin{array}{c}\text { Motor } \\
\text { sample }\end{array}$} & \multicolumn{4}{|c|}{ Number of broken bars } \\
\cline { 2 - 5 } & 0 & 1 & 2 & 3 \\
\hline 1 & $-52.9 \mathrm{~dB}$ & $-44.8 \mathrm{~dB}$ & $-35.5 \mathrm{~dB}$ & $-31.1 \mathrm{~dB}$ \\
\hline 2 & $-60.9 \mathrm{~dB}$ & $-49.7 \mathrm{~dB}$ & $-44.2 \mathrm{~dB}$ & $-40.9 \mathrm{~dB}$ \\
\hline 3 & $-60.4 \mathrm{~dB}$ & $-55.0 \mathrm{~dB}$ & $-52.7 \mathrm{~dB}$ & $-49.1 \mathrm{~dB}$ \\
\hline
\end{tabular}

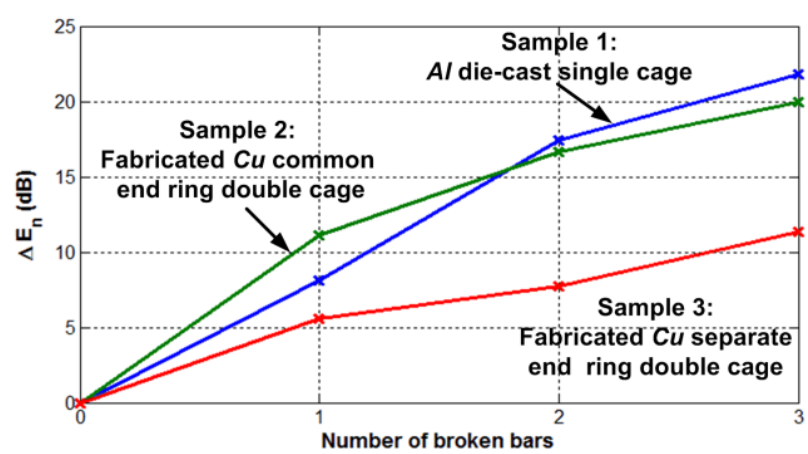

Fig. 13. Increase in the $\mathrm{dB}$ level of the fault quantification indicator $E_{n}$ with number of broken bars for motor samples 1, 2, and 3

13 with the FFT results shown in Fig. 4 since a direct comparison under identical conditions is not possible (Fig. 4(a)-(c) are MCSA results measured for samples 1,2 , and 3 , respectively). The type of load, signal pattern, or fault indicator, and how they are influenced by loads or transients is completely different since the FFT analyzes steady state, whereas the DWT analyzes transient conditions. However, the results are meaningful in that the fault can be clearly observed under the most unfavorable condition of no load, which is not detectable with FFT. It can also be observed in Fig. 13 that the difference between the single and double cage motor fault detection sensitivity is not as profound as in the FFT (Fig. 4) with the DWT transient analysis, as it mainly relies on detection at high slip when the current in the outer bar is dominant. The difference in sensitivity between the common and separate end ring rotors can be attributed to the relatively smaller current in the outer brass cage in sample 3 at startup due to the high resistance. The results clearly show that the use of the DWT transient analysis can be justified for outer cage fault detection for double cage motors.

\section{CONCLUSION}

A new technique for detecting outer cage faults for double cage induction machines under motor startup was proposed in this paper as a viable alternative to the FFT-based steady state frequency analysis techniques. The justification of using startup transient analysis is that 1) FFT-based methods can fail to detect the fault unlike in the case of single cage motors (small outer cage current), and 2) the fault signatures are expected to be strong under motor startup at high slip due to the large outer cage current. A method based on the DWT was proposed and verified experimentally on common and separate end ring fabricated copper rotor samples. The experimental study based on the application of DWT shows that the proposed method provides the following advantages for detection of double cage rotor faults compared to steady state FFT:

High sensitivity of fault detection:
- Motor is assessed at startup when influence of fault is strong due to large outer cage current

Improved reliability of fault detection:

- The qualitative ( $\Lambda$-shaped wavelet pattern) or quantitative (change in fault indicator) analysis are not influenced by load variations/oscillations, or noise as in FFT peaks.

- The joint of broken bar is most likely to be separated, and therefore, observable under startup due to maximum thermo-mechanical stresses

- Fault is observable under light load conditions since detection relies on the startup transient at high slip

Low hardware/computational requirements:

- The computational requirement of the proposed DWT algorithm based on the Mallat algorithm is very low, even in comparison with FFT [17].

- Speed/slip estimation is not required

Less testing restrictions:

- Testing and sensitive detection of single and double cage motors possible without load at motor shops or manufacturing facilities (reduced voltage startup or with high inertia load)

One limitation of startup fault detection is known to be the requirement of long startup time. However, this is not an issue when it comes to double cage motors since they are only used in applications that require loaded starts with long startup time.

\section{REFERENCES}

[1] T.A. Lipo, Introduction to AC machine design, Wisconsin Power Electronics Research Center, University of Wisconsin, 2004.

[2] H.A. Toliyat, G.B. Kliman, Handbook of electric motors, $2^{\text {nd }}$ edition, Marcel Dekker, 2004.

[3] M.G. Say, The performance and design of alternating current machines, Sir Isaac Pitman and Sons LTD., London, 1955.

[4] J. Mroz, "Temperature field distribution of a double squirrel-cage motor during startup," IEE Proc.-Elec. Pwr. Appl., vol. 152, no. 6, pp. 1531-1538, Nov. 2005

[5] R.F. Walliser, and C.F. Landy, "Assessment of interbar currents in double cage induction motors with broken bars," IEEE Trans. on Energy Conv., vol. 9, no. 1, pp.159-164, March 1994.

[6] S. Williamson, and M.A.S. Abdel-Magied, "Steady state analysis of double cage induction motors with rotor cage faults," IEE Proc.- Elec. Pwr. Appl., vol. 134, no. 4, pp. 199-206, July 1987.

[7] J. Park, B. Kim, J. Yang, K. Lee, S.B. Lee, E.J. Wiedenbrug, M. Teska, and S. Han, " Evaluation of the Detectability of Broken Rotor Bars for Double Squirrel Cage Rotor Induction Motors," Proc. of IEEE ECCE, pp. 2493-2500, Sept. 2010.

[8] P.L. Alger, and J.H. Wray, "Double and triple squirrel cages for polyphase induction motors," AIEE Transactions Part III - Power Apparatus and Systems, vol. 78, no.2, pp. 637-645, Jan. 1953.

[9] C.H. Lee, "A design method for double squirrel-cage induction motors," AIEE Transactions Part III - Power Apparatus and Systems, vol. 78, no.2, pp. 630-636, Jan. 1953.

[10] A. Bellini, F. Filippetti, C. Tassoni, and G.A. Capolino, "Advances in Diagnostics Techniques for Induction Machines," IEEE Trans. on Ind. Elec., vol. 55, no. 12, pp. 4109-4126, Dec. 2008.

[11] F. Filippetti, G. Franceschini, C. Tassoni, and P. Vas, "AI Tehcniques in Induction Machines Diagnosis Including the Speed Ripple Effect," IEEE Trans. on Ind. Appl., vol. 34, no. 1, pp. 98-108, Jan./Feb. 1998.

[12] G.C. Stone, and I. Culbert, "The testing tools," IEEE Ind. Appl. Mag., no. 14 , vol. 6, pp. 48-53, Nov./Dec. 2008. 
[13] EXP 4000 Users Manual, Baker Instrument Company - An SKF Group Company, Fort Collins, CO, Feb.2010.

[14] M. Riera-Guasp, J. Antonino-Daviu, M. Pineda-Sanchez, J. PerezCruz, and R. Puche-Panadero. "A general approach for the transient detection of slip-dependant fault components based on the Discrete Wavelet Transform" IEEE Trans. on Ind. Electr., vol. 55, no. 12, pp.4167-4180, Dec. 2008.

[15] S. H. Kia, H. Henao, and G. A. Capolino, "Diagnosis of broken bar fault in induction machines using discrete wavelet transform without slip estimation," IEEE Trans. on Ind. Appl., vol. 45, no. 4, pp. 14051415, July/Aug. 2009.

[16] F. Briz, M.W. Degner, P. Garcia, and D. Bragado, "Broken rotor bar detection in line-fed induction machines using complex wavelet analysis of startup transients," IEEE Trans. on Ind. Appl., vol. 44, no. 3, pp. 760-768, May/June 2008.

[17] C.S. Burrus, R.A. Gopinath and H. Guo, Introduction to Wavelets and Wavelet Transforms - A primer, Prentice Hall, 1998.

[18] J. Antonino-Daviu, M. Riera-Guasp, J. Roger-Folch, and M.P. Molina, "Validation of a New Method for the Diagnosis of Rotor bar Failures via Wavelet Transformation in Industrial Induction Machines," IEEE Trans. on Ind. Appl., Vol. 42, No. 4, pp. 990-996, July/Aug. 2006.

[19] Tsoumas, I.P.; Georgoulas, G.; Mitronikas, E.D.; Safacas, A.N.; "Asynchronous Machine Rotor Fault Diagnosis Technique Using Complex Wavelets," IEEE Transactions on Energy Conversion, vol.23, no.2, pp.444-459, June 2008.

[20] M. Blodt, D. Bonacci, J. Regnier, M. Chabert, and J. Faucher, "OnLine Monitoring of Mechanical Faults in Variable-Speed Induction Motor Drives Using the Wigner Distribution," IEEE Transactions on Industrial Electronics, vol. 55, pp. 522-533, 2008.

[21] M. Riera, J. Antonino, J. Roger-Folch, and M.P. Molina, "Detection of Broken Rotor Bars in Induction Machines through the Study of the Startup Transient via Wavelet Decomposition," Proc. of the 9th International Conference on Optimization of Electrical and Electronic Equipments OPTIM 2004, Brasov, Romania, May 20-21, 2004, pp. 39-46.

[22] J. Antonino-Daviu, S. Aviyente, E. Strangas, and M. Riera-Guasp, "A Scale Invariant Algorithm for the Automatic Diagnosis of Rotor Bar Failures in Induction Motors," Proc. of the 20th IEEE ISIE 2011. Gdansk, Poland, June 2011.

\section{BIOGRAPHIES}

Jose Antonino-Daviu (S'04/M'08) received his M.S. and Ph. D. degrees in Electrical Engineering, both from the Universitat Politècnica de València, in 2000 and 2006, respectively. He was working for IBM during 2 years, being involved in several international projects. Currently, he is Associate Professor in the Department of Electrical Engineering of the mentioned University, where he develops his docent and research work. He has been invited professor in Helsinki University of Technology (Finland) in 2005 and 2007 and in Michigan State University (USA) in 2010. He has over 60 publications between international journals, conferences and books.

His primary research interests are condition monitoring of electric machines, wavelet theory and its application to fault diagnosis and design and optimization of electrical installations and systems.

M. Riera-Guasp (M'95) received his M.Sc. degree in industrial engineering and his Ph.D. degree in electrical engineering from the Universitat Politècnica de València (Spain) in 1981 and 1987, respectively. Currently he is an associate professor in the Department of Electrical Engineering of the Universidad Politécnica de Valencia. His research interests include condition monitoring of electrical machines, applications of the wavelet theory to electrical engineering, and efficiency in electric power applications.

Joan Pons-Llinares received the M.Sc. degree in Industrial Engineering (Electrical Speciality) from the Universitat Politècnica de València (UPV, Spain) in 2007. After obtaining the M.Sc. degree, he focused his research interests in the Wavelet Theory and its applications to fault diagnosis of electrical machines. In November 2008 he joined the UPV as an Assistant Professor of Electrical Technology. He is currently pursuing his Ph.D.
Jongbin Park received the B.S. degree in Electrical Engineering from Korea University, Seoul, Korea in 2010, where he is currently pursuing his M.S. degree.

His research interests are in condition monitoring, diagnostics, and analysis of electric machinery.

Sang Bin Lee (S'95-M'01-SM' 07) received the B.S. and M.S. degrees from Korea University, Seoul, Korea in 1995 and 1997, respectively, and his $\mathrm{Ph} . \mathrm{D}$. degree from Georgia Institute of Technology, Atlanta, GA in 2001, all in Electrical Engineering.

From 2001 to 2004, he was with General Electric Global Research Center (GRC), Schenectady, NY. At GE GRC, he developed an interlaminar core fault detector for generator stator cores, and worked on insulation quality assessment for electric machines. From 2010 to 2011, he was with the Austrian Institute of Technology, Vienna, Austria, as a Research Scientist where he worked on condition monitoring of PM synchronous machines. Since 2004, he has been a professor of Electrical Engineering at Korea University, Seoul, Korea. His current research interests are in protection, monitoring and diagnostics, and analysis of electric machines and drives.

Dr. Lee was the recipient of the 6 prize paper awards from the IEEE Power Engineering Society, the Electric Machines Committee of the IEEE Industry Applications Society, and the Technical Committee on Diagnostics of the IEEE Power Electronics Society. He serves as an Associate Editor for the IEEE Transactions on Industry Applications for the IEEE IAS Electric Machines Committee

Ji-Yoon Yoo received the B.S. and M.S. degrees in Electrical Engineering from Korea University, Seoul, Korea, in 1977 and 1983, respectively, and his Ph.D. degree in Electrical Engineering from Waseda University, Tokyo, Japan, in 1987.

From 1987 to 1991, he was an Assistant Professor in the Department of Electrical Engineering, Changwon National University. He joined the Department of Electrical Engineering of Korea University in 1991, where he has performed active research on Control of Electric Machines and Drives and Power Electronics Converters. His current research interests include Modeling, Analysis, and Control of Hybrid Electric Vehicle Systems, and Flexible AC Transmission Systems.

Christian Kral (M'00-SM'05) received the Dipl.Ing. and Ph.D. degrees in electrical engineering from Vienna University of Technology, Vienna, Austria, in 1997 and 1999, respectively.

From 1997 to 2000, he was a Scientific Assistant with the Institute of Electrical Drives and Machines, Vienna University of Technology. Since 2001, he has been with the Austrian Institute of Technology, the former Arsenal Research, Vienna. From 2002 to 2003, he was on sabbatical as a Visiting Professor at Georgia Institute of Technology, Atlanta. His research interests include diagnostics and monitoring techniques, machine models, and the simulation of electric machines and drives.

Dr. Kral is a member of the Austrian Electrotechnical Association OVE and the Modelica Association. 